\section{Egg on the Face, $f$ in the Mouth, and the Overbite}

\author{
C. Loring Brace \\ Museum of Anthropology \\ University of Michigan, Ann Arbor
}

Professor Hockett has graciously asked me to convert the contents of my letter to him on his delightful essay, "Distinguished Lecture: F," (AA 87:263-281, 1986) to the format of a commentary for publication in the American Anthropologist. In his essay, he suggests that $f$ sounds are a "recent innovation in human history" that occur only after the form of the human occlusion changed from an edge-to-edge bite to an overbite, and he cites a paper that I wrote in 1962 as the basis for dating these two phenomena to the adoption of agriculture six or seven thousand years ago. Toward the end of his essay, however, he notes that he was discomfitted to realize that my view changed during the course of the succeeding decade and that I went on record in 1972 as observing that the European occlusion has been characterized by an overbite for no more than 200 years. Consequently he suggests that, if the more recent date is true, his whole thesis "goes down the tubes" (p. 276). He also remarked upon being further discomfitted by a comparable change of stance on the part of his other source of information on matters occlusal, the late Carleton S. Coon.

This then gives me the opportunity to explain why I changed my view. My original suggestion that the overbite accompanied a dietary change to an increased dependence on grain at the onset of the Neolithic was in the grand tradition of old-fashioned speculative natural history (cf. Kipling 1902), and I apologize for having misled Hockett and any others who may have accepted my earlier conclusions as the results of science. In any case, they have not stood the test of time and the check with actual data.

My interest in the form of the bite was originally stimulated, as was Hockett's, by Coon's observations-in my case by reading his account of the relation between age and occlusal form in the mountains of northern Albania in 1930 (Coon 1950:80-85). Coon raised questions concerning the possible role played by changes in foodstuffs and eating habits, but he wisely avoided any summary judgment other than noting that the difference between an edge-to-edge bite and an overbite was not genetically determined (1950:81). Others also have noted that, in such diverse examples as Australian Aborigines (Price 1938, 1939; Brace 1980) and Eskimos (Price 1936, 1939; Waugh 1937), the change from an edge-toedge to an overbite took place in the space of a single generation. The association between this change and the adoption of the diet of Western "civilization" has been duly observed. Many thoughtful observers have concluded that the edge-to-edge bite is simply a product of heavy wear, and that, with the switch to refined and processed foods, this effectively ceases and the "normal" overbite of the newly erupted dentition is simply retained throughout life (Campbell 1925:51-52; Begg 1954:302, 305).

Although this is a reasonable expectation, it turns out that there are so many exceptions to this generalization that it can only be regarded as part of the picture. Since my original "justso-story" was written, I have spent the succeeding quarter of a century collecting information on the various manifestations of the human dentition, past and present, and I have a good deal more confidence in my more recent conclusions.

Until very recently - that is, within the last two thousand years and, in most instances, much less - the normal human occlusion was in the form of an edge-to-edge bite. Furthermore, this was true even in populations where there was little or no observable tooth wear (Brace 1977:197-198). While a change in molar wear planes from flat to oblique does accompany the change from a hunting and gathering to an agricultural mode of subsistence (Smith 1983, 1984), the change in incisor relationships has been generally much more recent. Sir Arthur Keith in fact observed that the change to an overbite occurred in Europe only at the end of the 18th century and began first with high-status individuals (Keith 1924:135).

Although this does not coincide with any major change in foodstuffs, it does coincide with a major change in how they were eaten. Prior to that point, the accepted method of reducing ingested food to bite-sized proportions 
was to grasp it with the fingers of the left hand and thrust a portion into the mouth to be gripped by the front teeth and sliced off at lip level with the knife held in the right handwhat I have referred to as the "stuff and cut" school of etiquette (Brace 1977:199). Practiced since childhood, it would be this that prevents the continuing eruption of the incisors which is the source of the overbite. With the introduction of the fork into the standard table setting, the accepted procedure for creating bite-sized portions of food was drastically altered. From that point on, the item of gastronomic attention was pinned to the plate with the fork held in the left hand and processed with the knife held in the right prior to being popped into the mouth (Elias 1978[1939]:95, 104-107; Lévi-Strauss 1965, 1968; Brace 1977:200). The role of the incisors as clamps ceases at that moment, overeruption is no longer opposed, and the result is the deep modern overbite that is now thought of as being "normal."

In China, culinary accomplishments have reached levels unmatched anywhere else (Lin and Lin 1972; Brace, Shao, and Zhang 1984:490), despite claims to the contrary (Chelminski 1985), and modern practices of dining etiquette date at least from the Song Dynasty (A.D. 960-1279) (Chang 1973; Freeman 1977:153). In standard Chinese procedure, food is cut in the kitchen before cooking or serving - "we do not butcher at the table" to quote one derogatory reference to Western manners. Consequently, chopsticks, like the fork in the West, should serve as a symbol denoting the change in eating habits that leads to the development of the overbite (Brace 1977:200). Although I hesitate to state my case on the basis of a single instance, the one Song Dynasty individual I have been privileged to examine-Mr. Zhouyu, an "ancient dead body," formerly a graduate student of the Imperial College, preserved in the Shanghai Museum of Natural History (examined courtesy of Dr. Shu Yongqing)-displays the expected deep overbite.

Chinese eating customs along with many other cultural elements had been imported by the Japanese in great quantities during the Tang (A.D. 618-906) and early Song (Binyon 1908:6; Okakura 1956:31-34; Befu 1971:68), and it is no surprise to discover that the occlusion of the available Medieval Japanese is also characterized by an overbite (Suzuki 1956:186; Brace and Nagai 1982).

Whether it be in regard to the influences that shape the form of the occlusion or the selective forces that maintain the teeth themselves in usable form and size, it is appropriate to note that the important factor is not the nature of the food per se but what is done to it before it is eaten (Brace 1977:199, 1979:544). In Asia, the crucial food preparation practices became widespread a thousand years ago, while in the Western world, they accompanied the spread of the industrial revolution barely two hundred years back. The key to the situation in the West was appreciated by one Cary $\mathrm{S}$. Moeller in a quartet of limericks entitled "Orthodontophobia." The last two of these are appropriate for the present discussion, and I quote them here:

Dentists still put up a fight,

Against the thought that it might,

Just be everyday use,

That served to produce,

The norm of the edge-to-edge bite.

But the source of our dentists' confusion,

Is just a Platonic illusion;

Knives and forks are the cause,

Of the shape of our jaws,

In their post-industrial occlusion.

[quoted in Brace 1977:204]

Alas for Professor Hockett's lovely hypothesis. The ugly facts of the recency of the overbite leave him without a particular anatomical key to help locate a place and time for the genesis of $f$. His unsolved puzzle may well leave him with an itch as he says (p. 276), but whether or not he has egg on his face, he has given us much food for thought. Egg, after all, is edible-with or without an overbite.

\section{References Cited}

Befu, Harumi

1971 Japan: An Anthropological Introduction. San Francisco: Chandler.

Begg, P. Raymond

1954 Stone Age Man's Dentition: With Reference to Anatomically Correct Occlusion, the Etiology of Malocclusion, and a Technique for its Treatment. American Journal of Orthodontics 40:298-312, 373-383, 462-475, 517-531.

Binyon, Laurence

1908 Painting in the Far East: An Introduction to the History of Pictorial Art in Asia, Especially Ghina and Japan. London: Arnold.

Brace, C. L.

1977 Occlusion to the Anthropological Eye. In The Biology of Occlusal Development. J. A. McNamara, Jr, ed. Pp. 179-209. Ann Arbor, MI: Center for $\mathrm{Hu}$ man Growth and Development Craniofa- 
cial Growth Series, Monograph No. 7, University of Michigan.

1979 Krapina, "Classic" Neanderthals, and the Evolution of the European Face. Journal of Human Evolution 8:527-550.

1980 Australian Tooth-Size Clines and the Death of a Stereotype. Current Anthropology 21:141-164.

Brace, C. L., and M. Nagai

1982 Japanese Tooth Size, Past and Present. American Journal of Physical Anthropology 59:399-411.

Brace, C. L., Shao Xiang-qing, and Zhang Zhen-biao

1984 Prehistoric and Modern Tooth Size in China. In The Origins of Modern Humans: A World Survey of the Fossil Evidence. F. H. Smith and F. Spencer, eds. Pp. 485-516. New York: Alan Liss.

Campbell, T. D.

1925 Dentition and Palate of the Australian Aboriginal. Adelaide: Hassell.

Chang, K. C.

1973 Food and Food Vessels in Ancient China. Transactions of the New York Academy of Sciences 35:495-520.

Chelminski, Rudolph

1985 The Gluttonous Evolution of la cuisine française. Smithsonian 16:134-146.

Coon, Carleton S.

1950 The Mountains of Giants: A Racial and Cultural Study of the North Albanian Mountain Ghegs. Papers of the Peabody Museum of Archaeology and Ethnology, Harvard University 23:1-105.

Elias, Norbert

1978[1939] The Civilizing Process: The Development of Manners: Changes in the Code of Conduct and Feeling in Early Modern Times. Edmund Jephcoat, transl. New York: Urizen.

Freeman, Michael

1977 Sung. In Food in Chinese Culture. K. C. Chang, ed. Pp. 141-176. New Haven, CT: Yale University Press.

Keith, A.

1924 Concerning Certain Structural Changes Which Are Taking Place in Our Jaws and Teeth. In The Growth of the Jaws, Normal and Abnormal, in Health and Disease. J. C. Brash, ed. Pp. 133147. London: Dental Board of the United Kingdom.

Kipling, Rudyard

1902 Just So Stories for Little Children. London: Macmillan.

Lévi-Strauss, Claude

1965 Le triangle culinaire. L'Arc 26:19 27.
1968 L'Origine des manières de table. Paris: Plon.

Lin Hsiang Ju, and Lin Tsuifeng

1972 Chinese Gastronomy. New York: Pyramid.

Okakura, Kakuzo

1956 The Book of Tea. Rutland, VT: Tuttle.

Price, Weston A.

1936 Eskimo and Indian Field Studies in Alaska and Canada. Journal of the American Dental Association 23:417-437.

1938 Changes in Facial and Dental Arch Form and Caries Immunity in Native Groups in Australia and New Zealand Following the Adoption of Modernised Foods. Dental Items of Interest 60:107125.

1939 Nutrition and Physical Degeneration: A Comparison of Primitive and Modern Diets and their Effects. New York: Hoeber.

Smith, B. Holly

1983 Dental Attrition in Hunter-Gatherers and Agriculturalists. Ph.D. dissertation, Anthropology. Ann Arbor: University of Michigan.

1984 Patterns of Molar Wear in HunterGatherers and Agriculturalists. American Journal of Physical Anthropology 63:39-56.

Suzuki, Hisashi

1956 Medieval Japanese Skeletons From the Burial Site at Zaimokuza, Kamakura City. (In Japanese, English Abstract, pp. 171-190.) Anthropological Society of Nippon. Tokyo: Shoten.

Waugh, L. M.

1937 Influence of Diet on Jaws and Face of the American Eskimo. Journal of the American Dental Association 24:16401647.

\section{Reply to Hockings and Brace}

\section{Charles F. Hockett \\ Department of Anthropology \\ Cornell University}

Hockings's comments ("Air in F Minor," $A A 88: 184,1986)$ have to do with the correlation, proposed in my lecture, between agriculture and $f$-sounds.

The plusses on my Map 2 are for Lushai, Naga, Nicobarese, Palaung, Pashto, Persian, Shina, Sindhi, Tamil, and Toda. Hockings thinks there should be more. Great care must 